\title{
La, Pr, Nd microalloying influence on deformable heat resisting nickel alloy of the VZh175 type structure forming
}

\author{
E. B. Chabina ${ }^{\dagger}$ E. V. Filonova, B. S. Lomberg, M. M. Bakradze \\ †chabinaeb@viam.ru
}

FSUE “All-Russian Scientific-Research Institute of Aviation Materials”, Radio St. 17, 105005 Moscow, Russia

\begin{abstract}
By high-allowing metal physical and heat physical techniques complex means lanthanum, prazeodim and neodim separate influence on deformable high-heat resisting Ni-Co-Cr-Al-Ti-W-Mo-Nb alloying system nickel base alloy structure forming features are investigated. Three model material compositions structural and phase conditions were studied after heat treatment. It is shown that lanthanum, prazeodim and neodim individual influence on quantity of phases, grain and interphase boundaries structure change and material heat physical characteristics variously. These alloys class structure represents $\gamma^{\prime}$ - solid solution grains with primary $\gamma^{\prime}$-phase particles, evenly distributed on grain boundaries. The alloy contains niobium and titanium based carbides MC, being formed at material crystallization stage during melting. Solid solution in grains is strengthened by secondary $\gamma^{\prime}$-phase particles. Grain boundaries are strengthened by $\gamma^{\prime}$-phase, chrome and molybdenum based carbides and borides particles. At introduction in the material rare earth elements (RZE) complicated structure different sizes and morphology nickel and RZE based intermetallid phases, which are evenly distributed in material volume, are formed. They also allocated on grain and $\gamma / \gamma^{\prime}$ interphase boundaries, in addition strengthening them. Material structure change distinctions are revealed: maximum quantity grain and $\gamma / \gamma^{\prime}$ interphase boundaries secondary carbides, borides and intermetallid phases with RZE after heat treatment are containing at composition with the prazeodim; composition with the neodim differs by the maximum nanodimensional $\gamma^{\prime}$-phase quantity and the minimum secondary intermetallid phase with RZE quantity. Containing lanthanum, prazeodim and neodim compositions differ with temperature and total warmth of endothermic effect of carbide, boride and intermetallic phases dissolution.
\end{abstract}

Keywords: microalloying, rare earth elements (RZE), microstructure, phase composition.

\section{Introduction}

Microalloying is one of the tools to increase the quality of hightemperature Ni-based alloys without changing significantly the chemical and phase equilibrium composition, and it is developed from the perspective of optimization of the concentration inhomogeneity of an actual structure [1-3]. The notion of microalloying, i.e. alloying with very small (on the order of one tenth to one hundredth of percent) doses of components, is true only for a concentration averaged in the whole volume of a metal. Normally, the elements used for microalloying get distributed inhomogeneously in a material's structure, and their concentration in separate local zones may be one or even two orders of magnitude higher than the average concentration and, consequently, it now becomes comparable with the content of alloying elements [4-6]. For the selection of microalloying, it is required to study in detail the structure of the alloys and the state of their interior interfaces (grain and subgrain boundaries, interphase boundaries, matrix-particle boundaries), where, as a rule, both harmful impurities and useful surfaceactive microadditions are segregated, their confrontation determining to a great extent the properties of alloys [6]. Therefore, the optimum content of microadditions cannot be independent of either the quantity and distribution of harmful impurities or the structural features of an alloy.
The experience in the investigation and application of microalloying demonstrates that, despite the fact that the effect of micro-components may vary from one addition to another, and from one alloy to another, there are still common regularities in the complex mechanism of microalloying. Owing to a high chemical activity and peculiar physical properties of rare earth elements (RZE), boron, carbon and other microadditions, they influence very effectively the kinetic and thermodynamic characteristics of interfaces (the interphase energy decreases, which leads to refinement of phase precipitates; interfacial diffusion slows down; cohesion increases and, as a consequence, crack propagation and pore nucleation are hindered) and enhance the homogeneity of the structure and the structural stability of alloys [5]. Microadditions play a very important role in neutralizing harmful impurities: they bind them into stable chemical compounds with a favorable morphology or expel them from interfaces.

The modern approach to microalloying, based on the generalization and analysis of a large amount of experimental data, consists in a joint introduction into an alloy of several elements in the strictly optimum quantity, exceeding which may lead to a sharp decline in the characteristics, sometimes even to a level below the values of the initial material $[4,5]$.

At the present time, for the microalloying of hightemperature deformable nickel alloys such elements are used 
as $\mathrm{Mg}, \mathrm{Sc}, \mathrm{Zr}, \mathrm{B}$, as well as the rare earth elements $\mathrm{Y}, \mathrm{La}, \mathrm{Ce}$ [7-11].

Microalloying with RZE has a significant effect on the properties and structure of high-temperature nickel alloys $[8,9]$. From the 14 lanthanides belonging to group IIIb of Mendeleev's periodic table of elements, it is lanthanum and cerium that are mostly used for the microalloying of nickel high-temperature deformable alloys [12-14]. Taking into account the fact that lanthanides have similar physical and chemical properties, it is interesting to study the possibility of using microalloying with praseodymium, neodymium and other elements of this group $[9,15,16]$. In spite of the similarity in the physical and chemical properties of lanthanides, they have different electronic structures, atomic radii, valencies.

The aim of the present investigation is to study the features of the separate effect of lanthanum, praseodymium, neodymium on structure formation in a deformable hightemperature nickel alloy of the VZh175 type (the $\mathrm{Ni}-\mathrm{Co}-\mathrm{Cr}-$ $\mathrm{Al}-\mathrm{Ti}-\mathrm{W}-\mathrm{Mo}-\mathrm{Nb}$ alloying system).

\section{Materials and experimental techniques}

Using a set of high-resolution metal-physical and thermophysical techniques [17], including electron microscopy (scanning electron microscopy and transmission electron microscopy using foils), electron backscatter diffraction, electron microprobe analysis (using polished sections with a locality of $1 \mu \mathrm{m}^{2}$ and foils with a locality of $20 \mathrm{~nm}$ ) and differential scanning calorimetry, the structural and phase state of a high-temperature nickel alloy belonging to the VZh175 type, of three model compositions, melted from the material of a single basic heat (composition, mass $\%$ : bas. Ni-14.8Co-10.2Cr-3.9Al-2.5Ti-3.1W-4.4Mo-4.2Nb), was investigated.

From the material of the basic heat, 3 electrodes with a weight of $10 \mathrm{~kg}$ each were produced, then remelted in a vacuum-induction furnace in a $10 \mathrm{~kg}$ crucible and cast into ingots. RZE (lanthanum, praseodymium and neodymium) were introduced into the melt. According to the results of chemical analysis, the residual content of RZE in the material amounted to: composition 1 - La 0.03 mass \%; composition 2 Nd 0.03 mass \%; composition 3 - Pr 0.04 wt. \%. The produced ingots were deformed by upsetting on a hydraulic press and heat-treated according to the standard regime for alloys of this class, in particular: quenching from the temperature of complete dissolution of the strengthening $\gamma^{\prime}$-phase and twostep aging to ensure the most complete precipitation of the secondary $\gamma^{\prime}$-phase [4].

The material's structure and phase composition were investigated in the heat-treated condition. The microstructure and the grain boundary misorientations were studied by scanning electron microscopy in secondary and backscattered electron imaging modes on a JSM-6490LV scanning electron microscope (SEM) with attachments for electron microprobe analysis INCA 450 and for electron back-scatter diffraction analysis INCA HKL. The local phase composition was studied using polished sections with a locality of $1 \mu \mathrm{m}^{2}$ by electron microprobe analysis (EMPA) on a JCMA-733 facility.
The dislocation structure, microstructure and composition with a locality of $20 \mathrm{~nm}$ were studied using foils on a JEM200CX transmission electron microscope (TEM) with an Inca Energy 250TEM energy-dispersive microanalysis system. The phase transformations in the material with different RZE contents were studied by differential scanning calorimetry (DSC) on a 404 F1 NETZSCH differential scanning calorimeter during heating with a rate of $20 \mathrm{~K} / \mathrm{min}$ in helium medium in a temperature range of 20 to $1260^{\circ} \mathrm{C}$.

\section{Results and discussion}

The structure of the alloys of this class represents grains of the $\gamma$-solid solution with primary particles of the $\gamma^{\prime}$-phase, uniformly distributed at grain boundaries. The alloy contains niobium- and titanium-based MC carbides forming at the stage of material crystallization during melting. Solid solution inside the grains is strengthened by particles of the secondary $\gamma^{\prime}$-phase, including nano-sized ones. Grain boundaries are strengthened by particles of the grain-boundary $\gamma^{\prime}$-phase, chromium- and molybdenumbased carbides and borides $[8,15]$. Study of the material of three model compositions has shown that their structure is identical: g-solid solution grains having a size of $20-30 \mu \mathrm{m}$ with primary particles of the $\gamma^{\prime}$-phase having a size of 2.0-5.0 $\mu \mathrm{m}$, uniformly distributed at grain boundaries. In the alloy there is a small quantity of primary $\mathrm{Nb}$ - and Ti-based MC carbides and uniformly distributed in the material's volume intermetallic phases with a complex composition, based on nickel and RZE (RZE = La for composition 1; Nd for composition 2; Pr for composition 3), having a size of 3.0$7.0 \mu \mathrm{m}$ (fig. 1). The RZE content in such phases is variable and varies in a range of 10 to $14 \%$ mass $^{1}$. Also, these phases include almost all of the alloy's elements. In the material without RZE, such phases are absent. Intermetallic phases containing RZE form at the stage of material crystallization during melting, and partially dissolve during subsequent processing operations (homogenization, die forging, heat treatment). Solid solution inside the grains is strengthened by fine particles of the secondary $\gamma^{\prime}$-phase (particle size 0.1-0.3 $\mu \mathrm{m}$ ) and the nano-sized $\gamma^{\prime}$-phase (particle size 50-70 $\mathrm{nm})$. Grain boundaries are strengthened by particles of the grain-boundary $\gamma^{\prime}$-phase and secondary intermetallic phases containing RZE, as well as carbides and borides based on Mo (fig. 2). Intermetallic phases containing RZE also precipitate at boundaries of the primary particles of the $\gamma^{\prime}$-phase (interphase boundaries). In the material of all compositions, there are observed complex non-metallic inclusions having a size of 1-3 $\mu \mathrm{m}$ and a globular shape, containing RZE, sulfur, phosphorus, oxygen.

It has been established that there are differences in the quantity of secondary intermetallic phases containing RZE and of the nano-sized $\gamma^{\prime}$-phase between the compositions containing La, Pr, Nd. The largest quantity of secondary intermetallic phases is observed in composition 3 with praseodymium; and the smallest content - in composition

1 The composition of the intermetallic phase particles was determined using the EMPA method, with at least 25 particles analyzed for each model composition. 

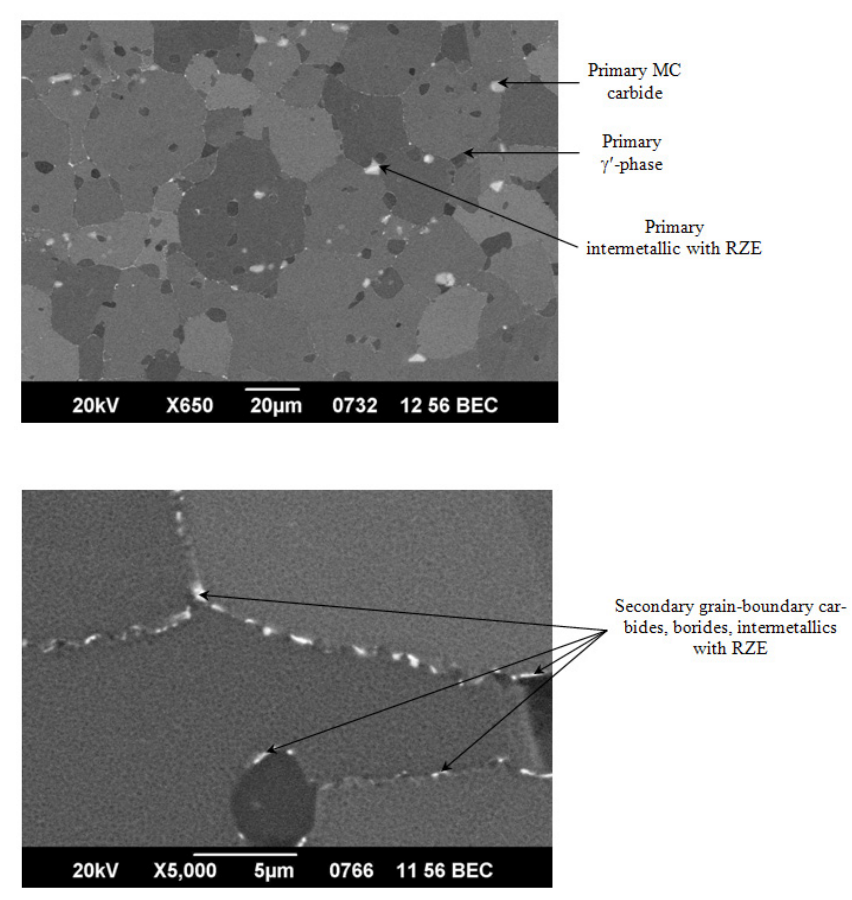

Fig. 1. Typical structure of the high-temperature $\mathrm{Ni}$ alloy with microalloying additions $\mathrm{La}, \mathrm{Pr}, \mathrm{Nd}$ (using as an example the material of composition 3, containing $\mathrm{Nd}$ ).

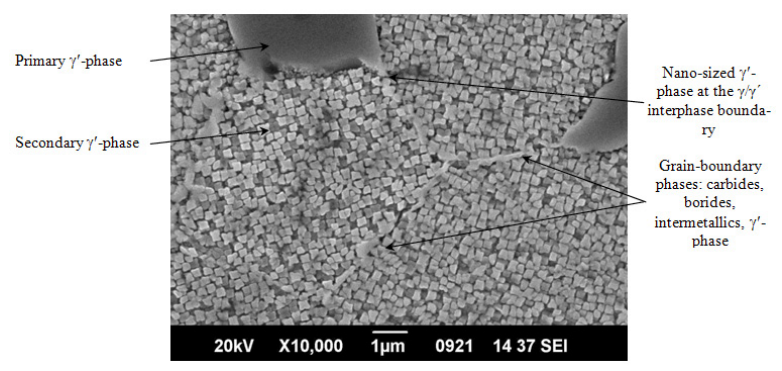

$\mathrm{a}$

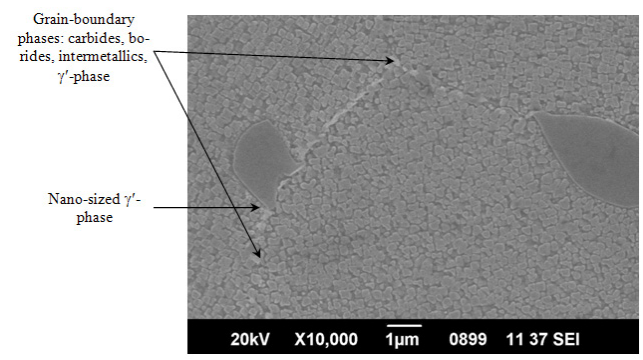

$\mathrm{b}$

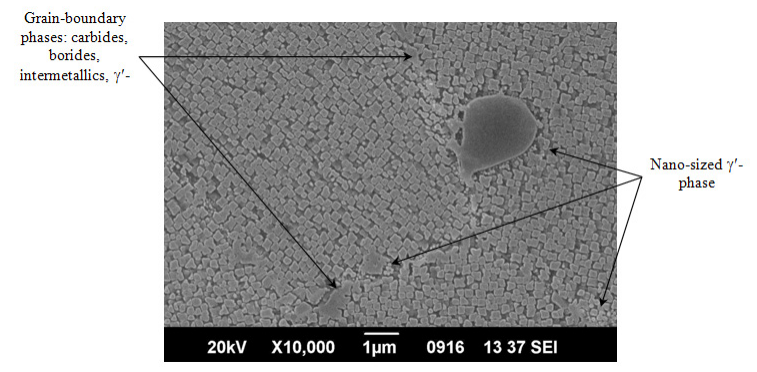

c

Fig. 2. Structure of grain boundaries and interphase boundaries: a - composition 1 (La), b -composition 3 ( $\mathrm{Pr}), \mathrm{c}$-composition 2 (Nd).
2 with neodymium. The nano-sized $\gamma^{\prime}$-phase precipitates predominantly at grain boundaries and interphase boundaries. In composition 1 with lanthanum, its quantity is the smallest (fig. 2, a), and in composition 2 with neodymium its quantity is the largest (fig. 2, c).

The method of electron backscatter diffraction was employed to study the following: grain size distribution, the misorientation of grains with respect to each other, the presence of boundaries of a special type, including twin boundaries. Analysis of the crystallographic orientation and grain size has revealed that in all the studied samples a homogeneous fine-grained microstructure with a grain size of $20-30 \mu \mathrm{m}$ is observed, and texture is absent in the samples. The distribution of grain boundaries in terms of misorientation angles is very close for all the samples: mainly $40-60^{\circ}$ (high-angle) boundaries prevail, there is a small quantity of low-angle (up to $15^{\circ}$ ) boundaries. In the grains there is a large quantity of twin boundaries (annealing twins). Analysis of the spectrum of special boundaries (grain boundaries with a high density of coincidence of lattice sites ( $\Sigma$ is the reciprocal density of coincidence sites), having an ordered structure with a specific period and a reduced energy) has shown that alongside with twin boundaries $\Sigma 3$ (misorientation angle $60^{\circ}$, twinning plane (111)), in the structure of the samples there are also special boundaries $\Sigma 5$, $\Sigma 9, \Sigma 11$ and others, although their fraction is much smaller than that of $\Sigma 3$ boundaries. Comparison has shown that the set of special boundaries is identical in all the samples. However, in the case of microalloying with praseodymium, there are observed more boundaries of the $\Sigma 11$ type $\left(35^{\circ} 10^{\prime}\right.$, (210)) than in other samples (fig. 3) ${ }^{2}$.

Using differential scanning calorimetry ${ }^{3}$, the effect of microalloying with $\mathrm{La}, \mathrm{Pr}, \mathrm{Nd}$ on the temperatures of the change in the phase composition of the deformable hightemperature Ni alloy was studied. Taking into account the
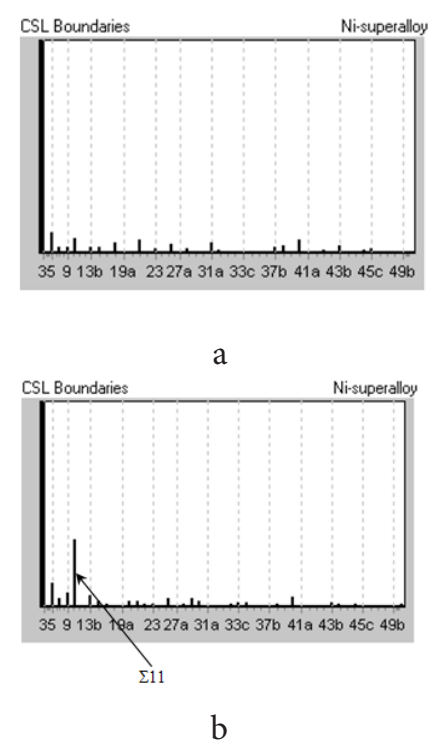

Fig. 3. Spectra of special boundaries, obtained by electron backscatter diffraction: a - composition 1 (La); b -composition 3 (Pr). X-axis shows the reciprocal density of coincidence sites, and the Y-axis shows the quantity of special boundaries.

2 Fig. 3a shows the spectrum of special boundaries of composition 1 (La), and the spectrum of special boundaries of composition $2(\mathrm{Nd})$ is completely identical to it.

3 The DSC studies were performed in cooperation with Yu.V. Loschinin. 
measurement error $\left( \pm 3^{\circ} \mathrm{C}\right)$, no significant changes in the temperature ranges of phase transformations are observed: the temperature of the dissolution start of the $\gamma^{\prime}$-phase (765$\left.770^{\circ} \mathrm{C}\right)$, the temperature of complete dissolution $\left(\mathrm{T}_{\mathrm{cd}}\right)$ of the $\gamma^{\prime}$-phase $\left(1157-1158^{\circ} \mathrm{C}\right)$, the solidus temperature $\mathrm{T}_{\mathrm{s}}(1210$ $1212^{\circ} \mathrm{C}$ ). There is observed a variation in the temperature and total heat value $\Delta \mathrm{H}$ of the endothermic effect of carbide, boride and intermetallic phases dissolution depending on microalloying (table 1). The dissolution starts with secondary phases having a size of 1-2 $\mu \mathrm{m}$ that precipitated at grain boundaries and interphase boundaries during the material's heat treatment, and ends with the dissolution of the primary phases that formed during the alloy's crystallization in the process of melting at temperatures close to the solidus temperature of the alloys. The maximum heat value $\Delta \mathrm{H}$ is found in composition 3 containing praseodymium, in which the largest quantity of secondary intermetallics containing RZE is observed. The minimum heat value $\Delta \mathrm{H}$ is recorded in the material of composition 2 containing neodymium, in which the quantity of secondary intermetallics containing RZE is minimum. This material also has the highest temperature of carbide, boride and intermetallic phases dissolution.

Studies of the structure of the samples containing the microalloying additions $\mathrm{La}, \mathrm{Pr}, \mathrm{Nd}$, by $\mathrm{TEM}^{4}$ using foils, have shown that in all the studied compositions, at grain boundaries and at boundaries of large $\gamma^{\prime}$-phase inclusions, there are observed particles of phases containing REE, which consist of fragments representing plates with a thickness of below $10 \mathrm{~nm}$. In the vicinity of grain boundaries and large inclusions there are observed $\gamma^{\prime}$-phase particles with a size of below $100 \mathrm{~nm}$. There are micro-twins present in the structure of the alloys. The twinning plane corresponds to crystallographic planes of the type (111). The largest quantity of micro-twins is found in composition 3 with praseodymium (fig. 4). In the structure of the samples with composition 3 (Pr), on the surface of the particles of the secondary $\gamma^{\prime}$-phase there are observed lamellar-shaped stacking faults (fig. 4, c). These stacking faults are observed only in the material of composition $3(\mathrm{Pr})$ and may represent thin (with a thickness of 1-2 atomic layers) plates of a new phase.

\section{Conclusions}

Analysis of the data obtained when studying the structure of the high-temperature nickel alloy containing the microalloying additions $\mathrm{La}, \mathrm{Pr}, \mathrm{Nd}$ after a complete heat treatment, has shown that the introduction of the microalloying additions into the alloy leads to the formation of additional intermetallic phases containing RZE, having different sizes and morphology, located in the materials' volume, at grain boundaries and interphase boundaries.

The effects of La, Pr, Nd on the change in the structure of grain boundaries and interphase boundaries are different. The composition with praseodymium differs from the compositions with lanthanum and neodymium by a large quantity of secondary carbides, borides and intermetallic phases containing RZE, present at grain boundaries 4 The TEM studies were performed in cooperation with D.V. Zaitsev.
Table 1. Temperature and total heat of the endothermic effect of carbide, boride and intermetallic phases dissolution

\begin{tabular}{|l|c|c|c|}
\hline & $\begin{array}{l}\text { Composi- } \\
\text { tion 1 (La) }\end{array}$ & $\begin{array}{c}\text { Composi- } \\
\text { tion 2 (Nd) }\end{array}$ & $\begin{array}{c}\text { Composi- } \\
\text { tion 3 (Pr) }\end{array}$ \\
\hline $\begin{array}{l}\text { Total heat of } \\
\text { carbide, boride } \\
\text { and intermetallic } \\
\text { phases } \\
\text { dissolution } \Delta \mathrm{H}, \\
\mathrm{J} / \mathrm{g}\end{array}$ & 1.46 & 0.96 & 1.82 \\
\hline $\begin{array}{l}\text { Temperature of } \\
\text { the maximum } \\
\text { dissolution of } \\
\text { carbide, boride } \\
\text { and intermetallic } \\
\text { phases T, }{ }^{\circ} \mathrm{C}\end{array}$ & 1188 & 1193 & 1186 \\
\hline
\end{tabular}
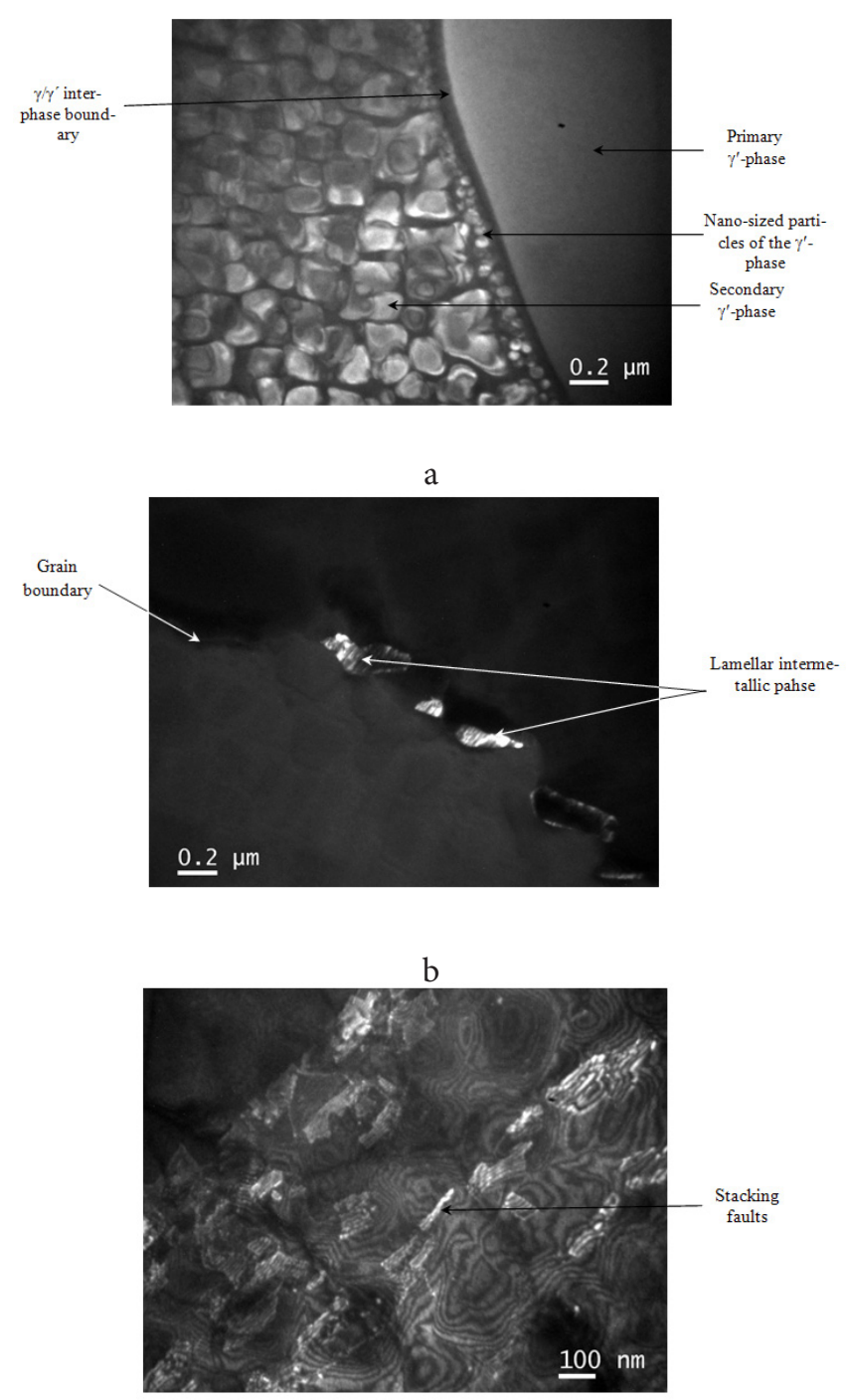

Fig. 4. Structure of the sample with composition $3(\mathrm{Pr}): \mathrm{a}-\gamma^{\prime}$-phase and the $\gamma / \gamma^{\prime}$ interphase boundary, b - lamellar intermetallic phase at a grain boundary, $\mathrm{c}$ - stacking faults at an interphase boundary. 
and at $\gamma / \gamma^{\prime}$ interphase boundaries after heat treatment; a large quantity of twins and special boundaries of the $\Sigma 11$ type $\left(35^{\circ} 10^{\prime},(210)\right)$; the presence, on the surface of the $\gamma^{\prime}$-phase particles, of lamellar-shaped stacking faults. The composition with neodymium differs from the compositions with praseodymium and lanthanum by a large quantity of the nano-sized g\$-phase and the minimum quantity of the secondary intermetallic phase containing REE. The compositions with $\mathrm{La}, \mathrm{Pr}, \mathrm{Nd}$ differ in the temperature and total heat of the endothermic effect of carbide, boride and intermetallic phases dissolution.

The obtained data concerning the effect of the additions $\mathrm{La}, \mathrm{Pr}, \mathrm{Nd}$ on the structure of deformable high-temperature nickel alloys can be used to develop the scientific fundamentals for controlling the processes of formation of the prescribed structure in the materials (in the first place, in interior interfaces) while designing new materials and improving the available ones.

Acknowledgements. This study was supported by RFBR under the Ofi_m Call for oriented basic research in relevant interdisciplinary topics of the year 2013, project No. 13-0812102.

\section{References}

1. Kablov E.N. Strategical areas of developing materials and their processing technologies for the period of up to 2030, Aviation Materials and Technologies. No. S, 7 (2012) (in Russian).

2. Cast Blades of Gas Turbine Engines: Alloys, Technology, Coatings. Under the general editorship of Kablov E.N., 2nd edition. Moscow, Nauka, 2006. 632 p. (in Russian).

3. Kablov E.N., Ospennikova O.G., Lomberg B.S. Comprehensive innovative technology of isothermal forging of superalloy discs in air in the superplasticity regime, Aviation Materials and Technologies. No. S, 129 (2012) (in Russian).

4. Superalloys. Vol. II / ed. by Ch.T. Sims, N.S. Stoloff, W.C. Hagel. Transl. from English. Moscow: Metallurgiya. 1995. Book 1. 384 p. (in Russian).

5. Bokstein S.Z., Kishkin S.T., Shalin R.E. Structural stability of structural materials. In the book: Aviation Materials at the Turn between XX-XXI Centuries. Moscow: VIAM. 1994. P. 547. (in Russian).

6. McLean M., Strang A. Effects of trace elements on mechanical properties of superalloys. Metals Technology, 11 (10), 454 (1984).
7. Lomberg B.S., Ovsepyan S.V., Bakradze M.M., Mazalov I.S. High-temperature $\mathrm{Ni}$ alloys for gas-turbine engine parts, Aviation Materials and Technologies. No. S, 52 (2012) (in Russian).

8. Lomberg B.S., Bakradze M.M., Chabina E.B., Filonova E.V. Relationship between the structure and properties of high-temperature $\mathrm{Ni}$ alloys for gas-turbine engine discs, Aviation Materials and Technologies. No. 2, 25 (2011) (in Russian).

9. Lomberg B.S., Bakradze M.M., Chabina E.B., Filonova E.V. Effect of microalloying elements on structural and phase stability and properties of heat-resistant deformable alloy (with long operation time), Metallurg. 9, 93 (2013) (in Russian).

10. Lomberg B.S., Ovsepyan S.V., Bakradze M.M. Peculiarities of the alloying and heat treatment of high-temperature $\mathrm{Ni}$ alloys for discs of gas-turbine engines of the next generation, Aviation Materials and Technologies. 2, 3, (2010) (in Russian).

11. Bakradze M.M., Ovsepyan S.V., Shugaev S.A., Letnikov M.N. The influence of quenching on structure and properties of nickel-based superalloy EK151-ID forgings, Works of VIAM. 9, Paper 01 (2013) (viam-works.ru) (in Russian).

12. Lomberg B. S., Ovsepyan S. V., Bakradze M. M. New high-temperature $\mathrm{Ni}$ alloy for discs of gas-turbine engines and gas-turbine plants, Materialovedenie. 7, 24 (2010) (in Russian).

13. Artyushov V.N., Kudrin A.A., Kirpichnikov M.S., Ponomareva L.L. Effect of microalloying on process ductility of high-temperature alloy KhN62MBKTYu (EP742-ID), Metallurgist. 55 (7-8), 591 (2011).

14. Kozlov E.V., Nikonenko E.L., Popova N.A., Koneva N.A. Effect of alloying by lanthanum on phase composition of super-alloys based on Ni-Al-Cr, Tambov University Reports, Series: Natural and Technical Sciences. 18(4), 1527 (2013) (in Russian).

15. Chabina E.B., Filonova E.V., Lomberg B.S., Bakradze M.M. All Materials. Encyclopedic directory. 6, 22 (2012) (in Russian).

16. Chabina E.B., Filonova E.V., Lomberg B. S., Zaitsev D.V. Structure formation in a nickel superalloy complexly alloyed with lanthanides, Russian Metallurgy 11, 904 (2014).

17. Chabina E.B., Alekseev A.A., Filonova E.V., Lukina E.A. The use of methods of analytical microscopy and X-ray diffraction analysis for the study of the structural-phase state of materials, Works of VIAM. 5, Paper 06 (2013) (viam-works.ru) (in Russian). 